\title{
Research on the Influence of Opinion Leaders on the Consumer Willingness of Post-90s and Post-00s
}

\author{
Lu Wang * \\ School of Economics and Management, Beijing Jiaotong University, China 100044 \\ *Corresponding author. Email: 15098360919@163.com
}

\begin{abstract}
This article explores whether and how the characteristics of opinion leaders and the quality of the information they convey affect the willingness to spend on overseas shopping in the post-90s and post-00s. Through factor analysis and Logit regression analysis, it is found that the popularity and professionalism of opinion leaders in this field has a significant positive impact on the consumption willingness of post-90s and post-00s; the quality of the information transmitted by opinion leaders has a positive impact on the consumption willingness of post-90s and post-00s. Significantly positive impact. Based on the research done, we put forward targeted suggestions on cross-border e-commerce platforms and settled companies, and attach importance to the influence of opinion leaders on consumers born in the 90s and 00s; enhance the visibility, professionalism and quality of information delivered by opinion leaders in this field, and play the leading role of opinion leaders and the function of stimulating consumption.
\end{abstract}

Keywords: Opinion leaders, Overseas shopping, Willingness to consume.

\section{INTRODUCTION}

The post-90s and post-00s have grown into a new consumer group with huge consumption potential, and their consumption amount and types are far more abundant and richer than those of post-70s and post-80s. At the same time, they prefer to seek advice from people who have purchased and used it as a reference for purchasing goods before making a purchase decision, which requires an opinion provider and platform. In recent years, social platforms for people to receive and disseminate information have continued to emerge. At the same time, the post-90s and post-00s have become major participants in the Internet and continue to be active on major social platforms. Rich social platforms provide opinion leaders with opportunities to spread their influence, provide important information to audiences, and thus have an important impact on consumers' purchase intentions. Therefore, it is very important to study the influence of opinion leaders on the post-90s and post-00s willingness to spend on overseas shopping.

According to current research on opinion leaders, overseas shopping models and consumer purchasing decisions, the post-90s and post-00s overseas shopping groups are rarely studied. Therefore, this article combines opinion leaders, overseas shopping behaviors and related theories and research results of consumption willingness, adopts a combination of literature analysis and empirical analysis, and collects data for research through questionnaire surveys. The post-90s and post-00s are consumer groups that have just grown up. Their economic strength and growth environment can show specific laws and characteristics. Taking the post-90s and post-00s as the research object can provide a research idea for future research. In practice, it can better meet the needs of market development and increase the profits of cross-border e-commerce platforms and settled enterprises.

\section{LITERATURE REVIEW AND THEORETICAL FRAMEWORK}

\subsection{Concept and Development of Opinion Leaders}

Turcote et al. pointed out that opinion leaders are very active in social networks, and they can use personal social networks to have more casual discussions with others to achieve an impact on the attitudes and behaviors of others ${ }^{[1]}$. At present, the community continues to increase the participation of opinion leaders, and the influence of opinion leaders on consumer behavior intentions has begun to be studied. 
Meng, Wei \& Zhu research found that opinion leaders can have a significant impact on the promotion and delivery of goods and services through various communication channels [2]. At the same time, opinion leaders use their reputation and professionalism to influence consumers. Chevalier\& Mayzli found that most explosive products have celebrity endorsements, and celebrities and some famous people reflect their popularity [3]. Bi Jidong pointed out that product information can be obtained by more professional opinion leaders in this field, and consumers accept the ability of opinion leaders to promote brands, so they can have a greater influence in related fields and improve consumers' recognition of product quality ${ }^{[4]}$. This article believes that opinion leaders refer to those people or groups that actively participate in the maintenance of interpersonal relationships and can exert a certain degree of influence on others. Based on their own popularity and professionalism, they often provide information and suggestions to other users and influence the opinions and behaviors of other users. Propose a hypothesis:

Ha1: The popularity of opinion leaders can have a positive impact on consumers' willingness of post-90s and post-00s to spend on overseas shopping.

Ha2: The professional performance of opinion leaders has a positive impact on consumers' willingness of post-90s and post-00s to spend on overseas shopping.

\subsection{The Concept and Development of Overseas Shopping}

Ma Zhen, Huang Junjie, Lin Nan once pointed out that overseas shopping is the behavior of overseas or overseas shopping through the Internet. Specifically, it can be divided into overseas purchasing agents, overseas e-commerce websites to place orders and forwarding companies to collect and send, and domestic cross-border e-commerce. Commercial purchasing and overseas direct mail direct purchase and other types ${ }^{[5]}$. Scholars' discussions on overseas shopping mainly focused on the phenomenon of overseas shopping, the popularization of overseas shopping knowledge, the development status of overseas shopping, development obstacles and countermeasures. However, there is very little research literature from the perspective of consumer behavior.

\subsection{Concept and Development of Consumer Willingness}

According to Fishbein's definition, willingness is the subjective probability of an individual performing a specific activity. To expand this concept, willingness to consume refers to the subjective possibility of consumers buying a certain product [6]. Dodds et al. pointed out that consumers' buying intention can reflect consumers' buying behavior to a certain extent, and the possibility of consumer intention is determined by consumer attitudes and some external factors [7]. This article believes that consumer willingness refers to the use of social platforms to allow consumers to browse, search and compare relevant information about products or services. The quality of the information makes it possible for consumers to purchase a certain product or service in the process of purchasing a product or receiving a service experience. Make the following assumptions:

$\mathrm{Hb} 1$ : The quality of the information delivered by opinion leaders has a positive impact on the consumers' willingness of post-90s and post-00s to spend on overseas shopping.

In summary, the analysis model of this article is proposed, as shown in Figure 1.

\section{RESEARCH DESIGN AND VARIABLE MEASUREMENT}

\subsection{Research Objects and Data Collection}

The survey object is the post-90s and post-00s overseas shopping groups. The questionnaire is issued in two ways, online and offline. Online questionnaire survey channels are mainly released through "Questionnaire Star". The offline survey method is mainly to distribute questionnaires to college students and young office workers. A total of 224 questionnaires were issued, 20 were invalid questionnaires, and 204 valid questionnaires were obtained. The questionnaire response rate was $83 \%$.

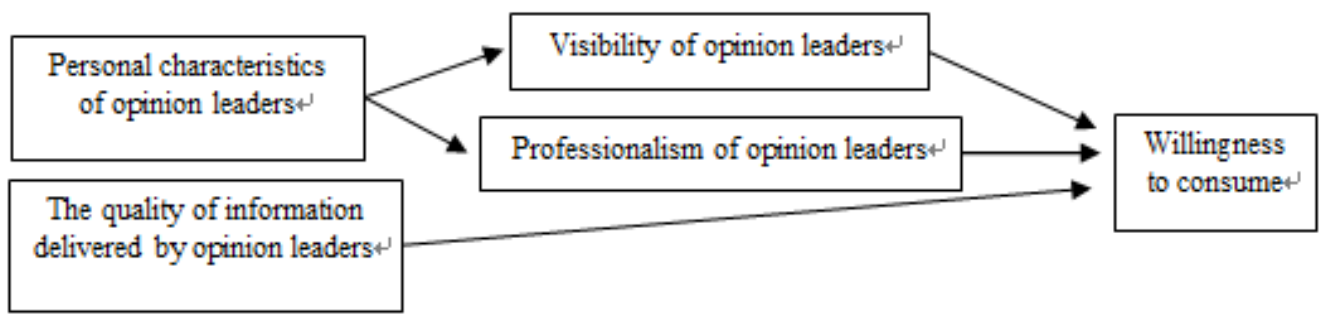

Figure 1 Model construction diagram 
Table 1. Descriptive statistics of the sample

\begin{tabular}{|c|c|c|c|}
\hline Question & Options & Number of people & Percentage \\
\hline \multirow{2}{*}{ Gender } & male & 89 & $43.63 \%$ \\
\hline & female & 115 & $56.37 \%$ \\
\hline \multirow{3}{*}{ Age } & under 16 & 18 & $8.82 \%$ \\
\hline & 16-24 years old & 130 & $63.73 \%$ \\
\hline & 25-30 years old & 56 & $27.45 \%$ \\
\hline \multirow{5}{*}{ Education } & Doctoral degree & 17 & $8.33 \%$ \\
\hline & master's degree & 30 & $14.71 \%$ \\
\hline & bachelor degree & 89 & $43.63 \%$ \\
\hline & Associate degree & 47 & $23.04 \%$ \\
\hline & Below high school degree & 21 & $10.29 \%$ \\
\hline \multirow{6}{*}{ Disposable income } & Below 500 yuan & 13 & $6.37 \%$ \\
\hline & 500-1000 yuan & 23 & $11.27 \%$ \\
\hline & 1000-2000 yuan & 61 & $29.9 \%$ \\
\hline & 2000-3000 yuan & 29 & $14.22 \%$ \\
\hline & 3000-4000 yuan & 30 & $14.71 \%$ \\
\hline & 4000 yuan or more & 48 & $23.53 \%$ \\
\hline \multirow{4}{*}{$\begin{array}{l}\text { Average monthly } \\
\text { number of overseas } \\
\text { shopping }\end{array}$} & Less than once & 25 & $12.25 \%$ \\
\hline & 1-3 times & 72 & $35.29 \%$ \\
\hline & 4-6times & 72 & $35.29 \%$ \\
\hline & 7 times or more & 35 & $17.16 \%$ \\
\hline \multirow{3}{*}{$\begin{array}{l}\text { Average monthly } \\
\text { spending on overseas } \\
\text { online shopping }\end{array}$} & Below 500 yuan & 87 & $42.65 \%$ \\
\hline & 500-1000 yuan & 80 & $39.22 \%$ \\
\hline & 1000 yuan or more & 37 & $18.14 \%$ \\
\hline \multirow{4}{*}{$\begin{array}{l}\text { Time to browse social } \\
\text { platforms every day }\end{array}$} & Less than 1 hour & 22 & $10.78 \%$ \\
\hline & $1-3$ hours & 71 & $34.8 \%$ \\
\hline & 4-6 hours & 74 & $36.27 \%$ \\
\hline & More than 6 hours & 37 & $18.14 \%$ \\
\hline
\end{tabular}

\subsection{Descriptive Statistics}

The ratio of male to female in the survey is close to $1: 1$, so gender in the data collected in this survey will not affect the results significantly. The age is concentrated in 16-24 years old, indicating that this age group is the main force of overseas shopping; overseas shopping consumption The average monthly number of overseas shopping is concentrated in 1-3 times, 3-6 times, indicating that the consumption frequency is higher after 90 and 00 . The average monthly overseas shopping amount is concentrated below 1,000 yuan, which shows that the overseas shopping amount is relatively small, which is in line with the income and consumption levels of $90 \mathrm{~s}$ and $00 \mathrm{~s}$. The time to browse social platforms is concentrated in 1-6 hours a day. It shows that the post-90s and post-00s spend more time on entertainment, and the time to pay attention to opinion leaders also increases.

\subsection{Reliability and Validity Analysis}

From the data, the Cronbach $\alpha$ reliability coefficients of opinion leaders' popularity, professionalism, the quality of their messages and the willingness to spend on overseas shopping are $0.875,0.828,0.894$, and 0.906 , which are all greater than 0.7 , which fully illustrates the questionnaire research data. The reliability is high. The $\mathrm{KMO}$ value of the questionnaire data is $0.956(>0.7)$, and the data shows that Bartlet's spheroid shape test $\operatorname{sig}<0.5$. Therefore, the data can be factorized while ensuring the validity of the data. Principal component analysis was used in the data analysis. 
Table 2. Coefficient

\begin{tabular}{|c|c|c|c|c|c|}
\hline & \multicolumn{2}{|c|}{ Non-standardized coefficient } & \multirow{2}{*}{$\begin{array}{c}\text { Standard } \\
\text { coefficient }\end{array}$} & $\mathrm{t}$ & Sig. \\
\cline { 1 - 3 } & $\mathrm{B}$ & Standard error & & 3.025 & 0.003 \\
\hline constant & 0.377 & 0.124 & & 2.111 & 0.036 \\
\hline Reputation & 0.128 & 0.061 & 0.135 & 4.628 & 0.000 \\
\hline professional & 0.248 & 0.054 & 0.279 & 8.169 & 0.000 \\
\hline
\end{tabular}

\subsection{Correlation Analysis}

Through Pearson test and significance (two-sided) test, there is a correlation between each variable. The absolute values of the correlation coefficients of the popularity, professionalism and the quality of the information delivered by opinion leaders are 0.808, 0.814 and 0.868 respectively. The results show that: the personal characteristics of opinion leaders are positively correlated with the influence of post- $90 \mathrm{~s}$ and post- $00 \mathrm{~s}$ overseas shopping willingness; opinion leaders The quality of the information delivered is positively correlated with the influence of the post-90s and post-00s' overseas shopping willingness.

\subsection{Regression Analysis}

This article contains a total of three independent variables: First, the personal characteristics of opinion leaders, including two factors of popularity and professionalism. The second is the quality of information delivered. These three independent variables were used to perform linear regression analysis on the relationship between the dependent variables 90 and 00 after overseas shopping willingness.

From the results of data analysis, it can be concluded that the $\mathrm{R}^{2}$ of the popularity of the opinion leader is 0.801 , and the Sig is less than 0.05 ; the $R^{2}$ of the professionalism of the opinion leader is 0.818 , and the Sig is less than 0.05 ; the $\mathrm{R}^{2}$ of the information quality of the opinion leader is 0.868 , and the Sig is less than 0.05 . 0.05 ; therefore, the popularity of opinion leaders is positively and significantly correlated with post-90s and post-00s overseas shopping willingness. That is to say, it is assumed that $\mathrm{H} 1 \mathrm{a}$ is established; the professionalism of opinion leaders is positively and significantly related to the post-90s and post-00s overseas shopping willingness. That is, assuming that $\mathrm{H} 1 \mathrm{~b}$ is established; the quality of the information delivered by opinion leaders is positively and significantly correlated with the post-90s and post-00s overseas shopping willingness that is, assuming $\mathrm{H} 2 \mathrm{a}$ is established.

\section{RESEARCH CONCLUSIONS}

This article reviews the relevant literature and concludes that opinion leaders may have an impact on the post-90s and post-00s' willingness to spend on overseas shopping. Research hypotheses are put forward based on the correlation of several variables, a questionnaire is designed, data is analyzed, and finally an appropriate method is selected for data analysis. Draw the following conclusions:

There is an obvious positive correlation between the popularity and professionalism of opinion leaders and the willingness to spend on overseas shopping after $90 \mathrm{~s}$ and $00 \mathrm{~s}$. After opinion leaders recommend products, the higher the perceived value of this overseas product by consumers born in the $90 \mathrm{~s}$ and $00 \mathrm{~s}$, the greater their willingness to consume.

The quality of information delivered by opinion leaders has a significant positive impact on post-90s and post-00s overseas shopping consumers. And it has the greatest impact on the consumption willingness of post-90s and post-00s overseas shopping. It shows that consumers pay more attention to the quality of information delivered by opinion leaders. The higher the quality of the information delivered by opinion leaders, the greater the probability of choosing overseas shopping after 90 s and 00 s.

\section{REFERENCES}

[1] Turcotte J, York C, Irving J, et al. News Recommendations from Social Media Opinion Leaders: Effects on Media Trust and Information Seeking $[\mathrm{J}]$. Journal of Computer-mediated Communication, 2015, 20(5):520 535.

[2] Meng F, Wei J, Zhu Q. Study on the Impacts of Opinion Leader in Online Consuming Decision[M]. IEEE,2011.

[3] Chevalier J A, Mayzlin D. The Effect of Word of Mouth on Sales: Online Book Reviews[J]. Journal of Marketing Research, 2006, 43(3):345 354.

[4] Bi Jidong. An Empirical Study on the Influence of Internet Word of Mouth on Consumers' Purchase 
Intention[J]. Journal of Information, 2009, 28(11): 46 51.

[5] Ma Zhen, Huang Junjie, Lin Nan. Research on the impact of the development of overseas shopping on college students' shopping behavior [J]. Science and Technology Economic Market, 2019(01): 108 110.
[6] FISHBEIN M, AJZEN I. Belief, Attitude, Iintention and Behavior: An Introduction to Theory and Research [J].Addison-Wesley, 1977(2):130 132.

[7] Dodds, W.B., Monroe, K.B, \&Grewal, D. 1991. Effects of price, brand, and store information on buyers' product evaluations, Journal of Marketing Research, 28(3):307 319. 